\title{
Type 2 diabetes and cancer: problems and suggestions for best patient management
}

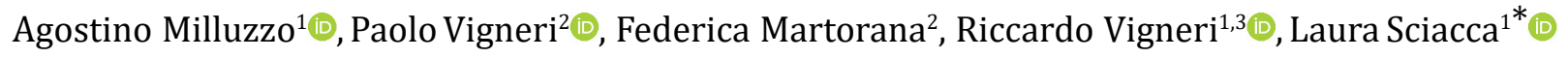 \\ ${ }^{1}$ Department of Clinical and Experimental Medicine, Endocrinology Section, University of Catania Medical School, 95122 \\ Catania, Italy \\ ${ }^{2}$ Center of Experimental Oncology and Hematology, Department of Clinical and Experimental Medicine, University of Catania, \\ A.O.U. Policlinico-Vittorio Emanuele, 95124 Catania, Italy \\ ${ }^{3}$ Institute of Crystallography, Catania Section, National Research Council, CNR, 95126 Catania, Italy
}

*Correspondence: Laura Sciacca, Department of Clinical and Experimental Medicine, Endocrinology Section, University of Catania Medical School, Via Palermo 636, 95122 Catania, Italy. Isciacca@unict.it

Academic Editor: Giovanni Targher, University of Verona, Italy

Received: May 29, 2020 Accepted: June 16, 2020 Published: August 31, 2020

Cite this article: Milluzzo A, Vigneri P, Martorana F, Vigneri R, Sciacca L. Type 2 diabetes and cancer: problems and suggestions for best patient management. Explor Med. 2020;1:184-204. https://doi.org/10.37349/emed.2020.00013

\begin{abstract}
Diabetes and cancer are widespread worldwide and the number of subjects presenting both diseases increased over the years. The management of cancer patients having diabetes represents a challenge not only because of the complexity and heterogeneity of these pathologies but also for the lack of standardised clinical guidelines. The diagnosis of cancer is traumatizing and monopolizes the attention of both patients and caregivers. Thus, pre-existent or new-onset diabetes can be overshadowed thus increasing the risk for short- and long-term adverse events. Moreover, drugs used for each disease can interfere with the clinical course of the concomitant disease, making challenging the management of these patients. Over the years, this issue has become more relevant because of the increased patients' life expectancy due to the improved efficacy of diabetes and cancer therapies.

The purpose of this review is to highlight what is known and what should be taken into consideration to optimise the clinical management of patients with diabetes and cancer. Due to the complexity of these diseases, a multidisciplinary, shared approach, including all the protagonists involved, is necessary to improve patients' quality of life and lifespan.
\end{abstract}

\section{Keywords}

Diabetes, cancer, glycaemic target, oral hypoglycaemic agents, anticancer therapy, chronic complications

\section{Introduction}

Diabetes and cancer are widespread diseases whose prevalence has continued to increase over the past decades placing a burden on clinical and public health systems. The world current prevalence of diabetes is estimated to be more than 400 million cases, rising to 650 million in the next two decades, with the majority 
of them affected by type 2 diabetes (T2D) [1]. Likewise, the last worldwide report of the International Agency for Research on Cancer reported 18 million new cases of cancer and almost 10 million cancer-related deaths in 2018 [2].

The growing prevalence of these diseases led to an increase of subjects affected by both T2D and cancer, triggering the effort of the scientific community to understand the link that underlies their onset. Both diseases are multifactorial disorders with complex, not fully understood, pathogenic features, and share many modifiable (unbalanced diet, sedentary, obesity, alcohol, and tobacco assumption) and not modifiable (sex, aging) risk factors [2,3]. In the last decades, the spread of westernised lifestyle has favoured a rapid increase of overweight prevalence together with other related adverse conditions, such as hyperinsulinemia, hyperglycaemia, inflammatory cytokines environment (TNF- $\alpha$, IL-6, IL-17, and TGF- $\beta$ ), which are involved in both T2D and cancer etiopathogenesis [2-4]. In particular, hyperinsulinemia, typical of overweight and T2D subjects, favours cells growth and together with the above-mentioned factors promotes cancer progression and aggressiveness [4-7]. In fact, most cancer cells, overexpressing the insulin receptor isoform A (IR-A), are more responsive to the mitogenic effect of both endogenous and exogenous insulin compared to the prevalently metabolic effects of the B isoform (IR-B) $[4,5,8]$.

The $8-18 \%$ of cancer patients are also affected by diabetes [9]. Confirming the mutual influence between diabetes and cancer, observational data suggest an increased risk of cancer in diabetes subjects. In particular, liver, breast, pancreas, colorectum, bladder, and endometrium cancer are more frequent in diabetic patients $[10,11]$. Moreover, patients with diabetes have higher cancer-specific mortality due to a higher tendency to infections, increased surgery and post-surgery mortality, and enhanced toxicity of therapies [12-14]. In addition, the complex patients' clinical status might induce the oncologist to reduce the dose of chemotherapy, thus reducing its effectiveness. Some evidence also suggests a possible increased risk of diabetes in cancer survivors, in particular in patients with pancreatic, kidney, liver, colorectal, and breast cancer [15-18]. This risk would be independent from traditional diabetes risk factors [18].

The clinical management of patients with both diabetes and cancer has several critical aspects, representing a major challenge. The coexistence of diabetes and cancer produces relevant clinical questions arising from the mutual influence of the two diseases. In regard to the diabetes, the main topics are about the level of glucose control to achieve, the drugs to use, and how to manage chronic diabetes complications. As for the cancer, it is discussed the importance to plan anticancer therapies in sight of the presence and severity of chronic diabetes complications, to keep in mind the glycaemic effects of supportive therapy with glucocorticoids (GCs), to manage nutritional aspects (lack of appetite, artificial nutrition) and the end of life. Furthermore, despite the growing number of patients with both diabetes and cancer, no standardised protocols or guidelines are currently available due to the multiplicity and heterogeneity of these patients' condition and the great variability of drugs' combination.

This review will summarise the present evidence on the major interferences of diabetic and oncologic drugs on the "cancer-diabetes disease", as well as the main critical issues in the treatment of patients affected by diabetes and cancer, with the aim to provide clinicians with some updated information for the best management of these patients.

\section{Glucose management: what goals and what drugs}

Cancer management engages much of the attention of both patients and physicians as demonstrated by a decreased adherence to diabetes therapies after cancer diagnosis $[19,20]$. Nevertheless, the glucose management in patients affected by both cancer and diabetes cannot be ignored or underestimated. Despite no randomised trial has been carried out to demonstrate the influence of glucose control on cancer-related outcomes, observational studies indicate that diabetes, mainly when uncontrolled, negatively influences cancer prognosis reducing the duration of remission and survival [21-24]. In a meta-analysis of 23 studies, Barone et al. [12] estimated a $41 \%$ increased risk of death in cancer patients affected also by diabetes. A significant increase of mortality was observed for breast, endometrium, and colorectal cancer [Hazard ratio (HR): 1.76, 1.61, and 1.32, respectively] [12]. The worsening of glucose control, often observed after cancer 
diagnosis, is also associated with an increased risk of tumour recurrence and mortality [25, 26]. Many factors contribute to determining these cancer-related adverse outcomes. First, diabetes increases susceptibility to infections, surgery/post-surgery mortality, and toxicity of therapies [12-14]. Secondly, diabetes may cause renal, cardiovascular, and neuropathic complications. Thirdly, hyperglycaemia negatively influences nutritional condition and the performance status [9]. For all these reasons, patients affected by both diabetes and cancer are often frail subjects and this could lead to reducing chemotherapy dosing and the chance of cancer recovery.

\section{What target for glycaemia and glycated haemoglobin?}

Few evidences are available on the management of glucose metabolism in cancer patients. A personalised approach is necessary, and the choice of glucose target should be primarily addressed by the patient's life expectancy and co-morbidities. In case of short life-expectancy (less than five years), the priority is to avoid the acute complications of glycaemia abnormalities (hypoglycaemia, ketoacidosis, and hyperglycaemic hyperosmolar syndrome), the hyperglycaemia-related osmotic symptoms (polyuria, polydipsia, and dehydration) and infections that could reduce patient's quality of life [27]. Conversely, for these patients, the prevention of diabetes-related micro- and macro-vascular complications represents a secondary goal: a target of glycated haemoglobin (HbA1c) between 8-9\% and glycaemic values between 120-270 mg/dL are reasonable $[28,29]$. Subjects with a particularly poor prognosis and a very short life expectancy (a few days or weeks), should be maintained within a glycaemic interval of $180-360 \mathrm{mg} / \mathrm{dL}[29,30]$.

However, in the last decades, due to the continuous improvement of anticancer therapies, an increasing proportion of cancer patients recovers had a long life expectancy, aiming to a normal lifespan. Consequently, glycaemic targets similar to diabetic patients without cancer should be pursued [27].

\section{What diabetes drugs?}

At present, there are no specific recommendations regarding the diabetes therapy for patients also affected by cancer. Provided that, only observational data are available, and the existing evidence is insufficient to advise how to modify diabetes therapy at cancer diagnosis. Several drug classes, many of whom introduced over the past two decades, with different mechanisms of action, efficacy, and tolerability profile, exist for diabetes care. The choice of the therapeutic approach should be driven by patient's characteristics, tailoring the most suitable strategy for each of them [31]. Nevertheless, due to the shortage of evidence and clinical trials, no evidence-based, personalised treatment recommendations are available for the management of patients with both diabetes and cancer. Clinicians have to consider many aspects to personalise the therapeutic approach: patient's comorbidities, the time onset of action and the adverse events (AEs) of diabetes drugs, their potential interactions with anticancer agents, and the safety related to the possible cancer progression or recurrence.

Insulin

Insulin therapy, for several reasons, is often required in T2D patients with cancer, above all for its efficacy and fast onset of action, being particularly useful in case of severe hyperglycaemia. Secondly, for the flexibility of insulin regimen, helpful to treat the acute and intermittent hyperglycaemia induced by both chemotherapy drugs-especially if cyclically administered-and GCs, often used to reduce the collateral symptoms of chemotherapy, to control the cancer-related pain, or as a component of chemotherapy in blood cancers [9]. Short-acting insulin analogues (lispro, aspart, and glulisine) should be preferred for the management of postprandial hyperglycaemia in cancer patients. Their fast onset of action and the possibility to inject after meals are useful when, in patients with nausea, vomiting, and difficulty to eat, food intake is not predictable [9, 32].

In patients with also uncontrolled fasting glucose, a strengthening of insulin therapy with a basal-bolus regimen could be necessary. When the introduction of a long-acting insulin analogue is required, insulin degludec and glargine $300 \mathrm{U} / \mathrm{mL}$ could be preferred for their greater flexibility in the timing of administration respect to glargine $100 \mathrm{U} / \mathrm{mL}$ or detemir $[9,33]$. Hypoglycaemia is the main risk of an insulin regimen. An accurate training of the patient and/or his/her caregivers regarding glucose self-monitoring, insulin injection technique, and titration is necessary to reduce this risk. The management of an insulin regimen, especially 
for patients insulin-naïve or with newly diagnosed hyperglycaemia, could be challenging. Inpatients with a relevant burden deriving from the oncologic disease, the diabetologist should consider the additional load deriving from a complex diabetes therapy.

Studies regarding the carcinogenic effects of long-acting insulin analogues provided uncertain and contrasting results. Due to the lack of conclusive evidence on this topic, the decision to use long-acting insulin analogues in diabetic patients with cancer should be evaluated based on metabolic and non-metabolic risks for each patient [34-37].

\section{Secretagogues}

Oral insulin secretagogues (sulphonylureas and glinides) stimulate endogenous insulin secretion causing hyperinsulinemia and are, therefore, associated with an increased risk of hypoglycaemia and weight gain.

Sulphonylureas are quite effective in reducing glucose level. The use of short-acting molecules (e.g., gliclazide), useful in the management of post-prandial hyperglycaemia, should be preferred for the lower risk of hypoglycaemia compared to the other molecules of this class (i.e. glibenclamide, glimepiride, and glipizide) $[37,38]$.

Repaglinide, a meglitinide with short-acting insulin secretagogue effect and different dosage regimen, is useful when meal intake is unpredictable [32].

The evidence concerning the risk of cancer in patients treated with sulphonylureas are conflicting and not univocal. Several observational studies focused on this issue, indicating an increased risk of breast cancer, although mitigated by subsequent, better designed analysis, and an increased cancer-specific mortality, mostly related to the use of glibenclamide $[3,39]$. Conversely, sulphonylureas seem to reduce the risk of ovarian and prostate cancer [3].

\section{Alpha-glucosidase inhibitor}

A molecule acting on post-prandial hyperglycaemia is acarbose, an alpha-glucosidase inhibitor which reduces the absorption of carbohydrates from the small intestine. Acarbose, compared to insulin and secretagogues, has both a lower effect in reducing post-prandial glucose level and a very low risk of hypoglycaemia. Nevertheless, the mild effect on glycaemia and the intestinal AEs (flatulence, abdominal pain, and diarrhoea), limit its use in the management of diabetes in cancer patients [9].

\section{Insulin sensitising agents}

The use of insulin sensitising agents (metformin and pioglitazone) in T2D patients with cancer is supported by the rational to contrast the insulin-resistance often enhanced by antineoplastic drugs and GCs.

A large amount of data is available for metformin, a biguanide widely used in T2D. In addition to the well-known glucose effect, preclinical and clinical studies suggested the anticancer properties of this drug. In vitro, metformin demonstrated an antiproliferative effect by reducing cancer cell proliferation as well as the epithelial-mesenchymal transition, and by inducing apoptosis [39]. A large number of observational studies suggest that metformin reduces the occurrence of several cancers, in particular colon-rectal, breast, prostate, liver, pancreas, gastrointestinal, ovarian cancer [10, 40, 41]. In addition, metformin reduces cancer mortality in comparison with other glucose-lowering agents [42]. Recent evidence from retrospective analysis showed a reduced gastric cancer risk in T2D treated with metformin [43]. Moreover, metformin seemed to increase the radiosensitivity of tumoural tissues: in a meta-analysis of 17 cohort studies, including about 14 thousand patients with different cancer type (prostate, head-neck, rectum, lung, oesophagus, and liver), Rao et al. [44] observed a better response of cancer tissues to radiation therapy and an improved overall survival in patients treated with metformin. Although the evidence, derived from retrospective clinical studies, is not strong enough to recommend metformin in all people with diabetes and cancer, metformin use is reasonable in absence of AEs (gastrointestinal disturbance) or contraindications (chronic kidney failure, contrast medium administration because of the risk of acute nephropathy, and systemic hypoxia) [27, 45].

Another class of oral insulin-sensitising drugs used in T2D are thiazolidinediones (TZDs). Pioglitazone is the only molecule available for human use after the withdrawal of rosiglitazone. These drugs are quite 
safe in cancer patients, except for a possible increased risk of bladder cancer, observed for pioglitazone in animal studies. Observational studies and meta-analysis did not reach definitive and univocal conclusions. In short, they neither excluded nor confirmed the enhanced risk for bladder cancer [46-49]. Thus, the use of pioglitazone should be carefully avoided in patients with bladder cancer or uninvestigated haematuria $[3,50]$. The slow onset of action could be a drawback in patients with acute, severe hyperglycaemia.

\section{Incretin system modulators}

The dipeptidyl peptidase-4 inhibitors (DPP4-I) and the glucagon-like peptide-1 receptor agonists (GLP1-RA) are diabetes drugs modulating the incretin system, increasingly used in T2D and potentially useful in cancer patients with diabetes. Preclinical and observational studies showed a possible increased risk of thyroid and pancreatic cancer related to incretin therapies [51-53]. Nevertheless, the evidence of this risk, resulting from studies with methodological critical issues, remained conflicting, inconclusive, and mitigated by subsequent observations [54-56].

The DPP4-I (sitagliptin, saxagliptin, vildagliptin, linagliptin, and alogliptin) have a mild efficacy and a slow onset of action that can reduce their use in patients with moderate-severe and acute hyperglycaemia. The few available findings regarding the influence of DDP4-I on cancer prognosis indicated a safety of these drugs on the risk of neoplasm progression, recurrence, and mortality [57, 58].

The GLP1-RA (exenatide, liraglutide, lixisenatide, dulaglutide, and semaglutide) are more effective in reducing glucose level compared to DPP4-I. Yet, they are related to gastrointestinal side effects (lack of appetite, nausea, vomiting, and weight loss) that are undesirable in patients with cancer.

\section{Sodium glucose transporter-2 inhibitors}

The newest class of oral diabetes drugs, the sodium glucose transporter-2 inhibitors (SGLT2-I) (empagliflozin, dapagliflozin, canagliflozin, and ertugliflozin), reduces plasma glucose by inhibiting renal glucose reabsorption and increasing urinary glucose excretion. These drugs are not only not linked to an increased risk of malignancies $[59,60]$, but preclinical studies also indicated, mainly for canagliflozin, an interesting anti-proliferative effect on liver cancer cells [61-65]. SGLT2-I are potentially useful to treat diabetes in cancer patients, although the increased risk of genitourinary infections, volume depletion, and euglycaemic diabetic ketoacidosis should be carefully considered.

\section{Anticancer therapies: the burden on glucose metabolism and chronic diabetes complications}

The detrimental effect of the most common cancer regimens on metabolic control represents a major issue in T2D patients. Many anticancer regimens may quickly affect glucose metabolism, particularly when GCs are adopted [66]. Furthermore, cancer therapies may play an independent role either on the onset or the progression of diabetes micro- and macro-vascular complications [67].

\section{Glucose metabolism}

Anticancer drugs may worsen glycaemic control in diabetic patients and induce transient or permanent hyperglycaemia in subjects with a normal carbohydrate tolerance before cancer diagnosis [18]. In the latter case, the evaluation of $\mathrm{HbA1c}$ is useful to distinguish a real hyperglycaemia onset during cancer treatment from a pre-existent, unrecognised glucose impairment [9].

Hyperglycaemia in cancer patients results from both anticancer drugs and support therapies. In particular, GCs-commonly used both to reduce the side effects of cancer therapies and as components of chemotherapy schedule-are known to induce insulin-resistance and hyperglycaemia $[66,68]$.

Glucose management during and immediately after cancer treatments represents a challenge for both clinicians and patients. Most of the evidence derives from observational studies while specific recommendations or guidelines are not available. It was observed that, a sub-optimal glycaemic control during cancer care results in unfavourable cancer-related outcomes and a lower survival $[25,26]$. Glucose control should be appropriate since the beginning of cancer chemotherapy, as demonstrated in a 12-week, longitudinal 
cohort of 18 T2D patients with various solid and blood malignancies, reporting that a poor glycaemic control at the start of chemotherapy increases the risk of short-term AEs (infections, hospitalisation, chemotherapy reduction or interruption) [69]. To promptly prevent the increase in glucose levels and variability, health professionals should knowledge the exact impact of the different cancer drugs on glycaemic control [70]. Nevertheless, the glycaemic effect of many chemotherapy agents is not fully understood and their short-term impact on glucose trend is still uncertain $[67,71]$.

Anticancer drugs influence glucose metabolism because of their interference on both insulin production or secretion and insulin sensitivity $[9,72]$ (Table 1). Many studies investigated the role of anticancer drugs in developing new cases of diabetes [18] while only few, mainly retrospective reports focused on the evaluation of cancer therapies effect on glucose levels of patients diagnosed with diabetes prior to the diagnosis of cancer. A meta-analysis of eight retrospective studies of T2D patients with different cancer types (prostate, breast, stomach, colon, and multiple myeloma), reported a worsened glucose control after cancer treatment [70]. A mild, statistically significant increase in HbA1c was found after 12 and 24 months since the beginning of cancer therapies. Interestingly, in patients who had undergone gastric surgery the rise of HbA1c level was not observed, probably because of the effects on food intake and weight loss. Conversely, patients in androgen deprivation therapy for prostate cancer had a more pronounced HbA1c worsening, remarking the detrimental effect of gonadotropin releasing hormone ( $\mathrm{GnRH}$ ) agonists, steroidal (cyproterone acetate) and nonsteroidal anti-androgens (flutamide, bicalutamide, and nilutamide) on body weight, fat composition, and insulin sensitivity [70, 73-78] (Table 1).

Table 1. Anticancer drugs effects on glucose metabolism

\begin{tabular}{|c|c|c|c|c|}
\hline Class/Agent & Glycaemia & HbA1c & c-peptide/insulin & Mechanisms \\
\hline Hormonal agents & $\uparrow[73]$ & $\uparrow[78]$ & & Increased Ins-Res \\
\hline \multicolumn{5}{|l|}{ - GnRH agonists (triptorelin, leuprorelin) } \\
\hline \multicolumn{5}{|l|}{$\begin{array}{l}\text { - Anti-androgens (cyproterone acetate, flutamide, } \\
\text { bicalutamide, nilutamide) }\end{array}$} \\
\hline $\begin{array}{l}\text { Glucocorticoids (prednisone, prednisolone, } \\
\text { methylprednisolone, dexamethasone) }\end{array}$ & $\uparrow[80,81]$ & $\uparrow[67,81]$ & & Increased Ins-Res \\
\hline $\begin{array}{l}\text { mTOR inhibitors (everolimus, sirolimus, } \\
\text { temsirolimus) }\end{array}$ & $\uparrow[87]$ & $\uparrow[67]$ & & Increased Ins-Res \\
\hline ICls & $\uparrow[89]$ & $\uparrow[89]$ & $\downarrow[89]$ & Reduced IP/S \\
\hline \multicolumn{5}{|l|}{ - Anti-CTLA-4 antibodies (ipilimumab) } \\
\hline \multicolumn{5}{|l|}{ - PDL-1 inhibitors (atezolizumab, avelumab) } \\
\hline \multicolumn{5}{|l|}{ - PD-1 inhibitors (nivolumab, pembrolizumab) } \\
\hline \multirow{2}{*}{$\begin{array}{l}\text { Somatostatin analogues (octreotide, lanreotide, } \\
\text { pasireotide) }\end{array}$} & $\uparrow($ pasireotide) [93] & $\uparrow[93]$ & & Reduced IP/S \\
\hline & $\downarrow$ (octreotide) [94] & & & Reduced GP/S \\
\hline$L$-asparaginase & $\uparrow[95,96]$ & & & Reduced IP/S \\
\hline $\begin{array}{l}\text { Alkylating agents (cisplatin, carboplatin, oxaliplatin, } \\
\text { cyclophosphamide, etc.) }\end{array}$ & $\uparrow[97-99]$ & $\uparrow[67]$ & & Reduced IP/S \\
\hline $\begin{array}{l}\text { Anti-microtubules (docetaxel, paclitaxel, } \\
\text { vinorelbine, vincristine, etc.) }\end{array}$ & $\uparrow[97,100]$ & $\uparrow[67]$ & & Reduced IP/S \\
\hline $\begin{array}{l}\text { Antimetabolites (5-fluorouracil, gemcitabine, } \\
\text { capecitabine, methotrexate, etc.) }\end{array}$ & $\uparrow[98,101]$ & $\uparrow[67]$ & $\downarrow[101]$ & Reduced IP/S ${ }^{*}$ \\
\hline Antracyclines (doxorubicin, epirubicin, etc.) & $\uparrow[97]$ & & & Reduced IP/S* \\
\hline
\end{tabular}

\footnotetext{
" indicates the uncertainty of the evidence on this item; GnRH: gonadotropin-releasing hormone; Ins-Res: insulin resistance; HbA1c: glycated haemoglobin; mTOR: mammalian target of rapamycin; ICls: immune checkpoint inhibitors; CTLA-4: cytotoxic T-lymphocyte 4-antigen; PDL-1: programmed cell death ligand-1; PD-1: programmed cell death-1; IP/S: insulin production/ secretion; GP/S: glucagon production/secretion
} 
We recently evaluated, in a retrospective real-world series of $168 \mathrm{~T} 2 \mathrm{D}$ patients with various malignancies, the short-term effect of different cancer drugs on glucose level [67]. In the six months after the beginning of cancer therapies, average $\mathrm{HbA} 1 \mathrm{c}$ significantly increased from $7.1 \%$ to $7.5 \%(P<0.005 \%)$, and in more than two thirds of patients we observed an increase in HbA1c levels greater than $0.5 \%$. In half of the patients, diabetes therapy was potentiated, and most of them introduced insulin, highlighting its well-known, widespread use in case of acute, severe, intermittent hyperglycaemia related to chemotherapy administration. Interestingly, the effect of each anticancer drug class on glycaemic control was also evaluated: a negative impact on glucose control was observed in patients treated both with high-dose GCs administration and with mTOR pathway inhibitors, cytotoxic antibodies, alkylating, anti-microtubules, and antimetabolite agents [67] (Table 1).

\section{Glucocorticoids}

The undesirable effect of GCs on glucose homeostasis is well reported and explained by an increased insulinresistance, liver gluconeogenesis, and a reduced insulin secretion [78, 79] (Table 1). T2D patients using GCs (prednisone, prednisolone, methylprednisolone, and dexamethasone) are likely to develop significant hyperglycaemia, mainly post-prandial, and should be alerted to enhance capillary glucose test checking prior or post lunch/evening meals [27, 71, 80, 81]. In these cases, the use of short-acting insulin analogues represent the first choice and the initial dose of $0.1 \mathrm{U} / \mathrm{kg}$ per meal is recommended. Supplementary insulin dosage could be necessary depending on the glycaemic response and the level of pre-prandial hyperglycaemia ( 0.04 or $0.08 \mathrm{U} / \mathrm{kg}$ per meal for pre-prandial glycaemic values between $200-300 \mathrm{mg} / \mathrm{dL}$ or above $300 \mathrm{mg} / \mathrm{dL}$, respectively) [82]. In patients already receiving insulin, prandial bolus should be increased according to capillary glucose levels [71]. To overcome the postprandial glycaemic rise of patients on once-daily GCs therapy, the Joint British Diabetes Societies suggest either the morning use of basal insulin (starting dose of $0.4 \mathrm{U} / \mathrm{kg}$ ) [82, 83], or high dose sulphonylureas in the morning (e.g., gliclazide up to $240 \mathrm{mg}$ in the morning and $80 \mathrm{mg}$ in the evening) [83].

mTOR pathway inhibitors

Molecules inhibiting specific components of different signaling pathways may cause hyperglycaemia. The mTOR pathway inhibitors (everolimus, sirolimus, and temsirolimus) used in breast cancer, advanced renal cell carcinoma, and neuroendocrine tumours (NETs) carry out their anticancer effect by inhibiting pathways normally involved in cell metabolism, proliferation, growth, and angiogenesis [84-86]. mTOR-inhibitors increase insulin-resistance and glycaemic levels in both diabetic and non-diabetic cancer patients [71, 87] (Table 1). In particular, everolimus induces hyperglycaemia in 10-15\% of cases, therefore requiring glycaemic surveillance [88] (Table 1).

\section{Immune checkpoint inhibitors}

In the last decade, targeted therapies modulating the immune response against cancer cells have acquired a relevant role in the treatment of metastatic melanoma, non-small-cell lung cancer, renal cell carcinoma, bladder carcinoma, head and neck cancer, and lymphomas [72].

Anti-cytotoxic T-lymphocyte 4-antigen antibodies (anti-CTLA-4 Abs), PDL-1 inhibitors, and PD-1 inhibitors could trigger an immune response against pancreatic beta cells and the onset of autoimmune diabetes in about $1 \%$ of treated patients [89-91] (Table 1 ). Hyperglycaemia induced by ICIs is often acute and severe. A meta-analysis of Akturk et al. [89] indicates an onset of hyperglycaemia after a median of 49 days since the first dose of drug, a mean values for glycaemia and HbA1c of $602 \mathrm{mg} / \mathrm{dL}$ and $7.9 \%$, respectively, and a diabetic ketoacidosis in $76 \%$ of cases. To date, no data are available on glucose trend in T2D patients treated with these drugs. Furthermore, considering the potentially life-threatening onset of ICIs-related hyperglycaemia, a careful clinical and biochemical monitoring is recommended.

\section{Somatostatin analogues}

Particular attention should be given to patients treated with somatostatin analogues (SST-A) (octreotide, lanreotide, and pasireotide) for acromegaly and NETs. Physiologically, somatostatin (SST) binds pancreatic receptors inhibiting insulin and glucagon release [92]. A dual effect of SST-A on glucose homeostasis has been 
observed, and this is explained by the different affinity of these drugs for SST receptors (SSTR) [72] (Table 1). Pasireotide strongly inhibits insulin release binding SSTR5 with high affinity. Muhammad et al. [93] reported an increase of glucose values in $88.5 \%$ of acromegalic patients treated with pasireotide for 24 weeks, and of $\mathrm{HbA1c}$ from $6.1 \%$ to $7.8 \%$. Moreover, the percentage of patients with diabetes increased from $32.8 \%$ to $68.9 \%$ after six months. Otherwise, the treatment with octreotide has been related to hypoglycaemic events because of its preferential activation of SSTR2 and consequent suppression of glucagon production [94].

$L$-asparaginase

$L$-asparaginase, used in patients with acute lymphoblastic leukaemia, reduces insulin secretion depleting $L$-asparagine in beta cells [9]. Moreover, a pancreatic cytolysis is reported in $7 \%$ of cases $[95,96]$ (Table 1 ).

\section{Classical cytolytic chemotherapy}

Alkylating agents, anti-microtubule agents, antimetabolites, and topoisomerase inhibitors are still widely used, representing the mainstay of many cancer treatments [71]. Their glycaemic effect in T2D patients is not fully understood due to the lack of longitudinal, prospective studies [66, 67]. Understanding of these molecules' influence on glucose homeostasis is also hindered by the multidrug chemotherapy regimens, often including GCs, which make exploring the role of each drug difficult, highlighting the need of targeted longitudinal trials. The available data indicate the onset of hyperglycaemia in a subset of patients receiving these drugs [66, 71] (Table 1). A systematic review by Hershey et al. [66], including 22 studies of patients with solid cancers, showed that cisplatin (alkylating agents) [97-99], docetaxel and vinorelbine (antimicrotubule agents) [97, 100], 5-fluorouracil (antimetabolites) [98, 101], and doxorubicin (topoisomerase inhibitors) [97] are associated with various degrees of hyperglycaemia in patients previously not affected by diabetes. Nevertheless, these findings were not fully consistent in all studies, as they did not support a causal relationship between the anticancer drug and the occurrence of hyperglycaemia [66]. Our retrospective series of T2D patients with various malignancies showed put forward similar suggestions [67], indicating the same classes of anticancer drugs reported by Hershey et al. [66] among those at major risk to increase HbA1c level.

\section{Chronic diabetes complications}

The primary aim for all diabetic patients is to avoid the long-term micro- and- macro-vascular complications, whose onset is closely related to glucose control. For several reasons (reduced adherence to diabetes therapies, anticancer therapies, etc.), after cancer diagnosis, glucose control could get worse [19, 20,67]. Additionally, anticancer drugs either could favour, both directly and indirectly (increasing glycaemia), the onset of diabetes vascular complications or exacerbate the progression. Their prevention is mandatory mainly in patients with good life expectancy. Furthermore, also in patients with an uncertain or bad cancer prognosis, the renal, ocular, cardiovascular, and neuropathic condition should be monitored. In fact, these organs' failure could lead to stopping or weakening anticancer therapies reducing the tumour response $[102,103]$.

Few data exist regarding the short- and long-term impact of anticancer chemotherapies on diabetes vascular complications, and no specific recommendations on their management in cancer patients are available.

Nephropathy

A negative effect on renal outcomes has been observed in T2D patients treated with various anticancer drugs [67] (Table 2). A significant increase of serum creatinine and reduction of the estimated glomerular filtration rate (eGFR) occurred during the six months following chemotherapy. In about $10 \%$ of patients, a detrimental effect was observed also on microalbuminuria. The drug classes more likely to cause renal AEs were mTOR and kinase inhibitors [67]. Everolimus and temsirolimus are known to increase the level of creatinine in up to $10 \%$ of treated patients [104]. This is probably due to the hyperglycaemic effect of mTOR inhibitors more than to an intrinsic, detrimental effect of these molecules on renal cells $[105,106]$ (Table2).

Tyrosine-kinase inhibitors (TKIs), in particular pazopanib, sunitinib, axitinib, sorafenib, could increase urinary protein levels (asymptomatic albuminuria or nephrotic syndrome) [107, 108]. Similar AEs were reported for bevacizumab and aflibercept, monoclonal antibodies directed against the vascular endothelial growth factor (VEGF), with an incidence between 1\% and 38\% across clinical trials [108] (Table2). 
Table 2. Anticancer drugs effects on renal, retinal, neuronal and cardiovascular events

\begin{tabular}{|c|c|c|c|c|}
\hline Class & Agents & Adverse outcomes & Mechanisms & References \\
\hline \multicolumn{5}{|l|}{ Nephropathy } \\
\hline $\begin{array}{l}\text { mTOR } \\
\text { inhibitors }\end{array}$ & $\begin{array}{l}\text { Everolimus } \\
\text { Temsirolimus }\end{array}$ & $\begin{array}{l}\text { Increased creatinine } \\
\text { Increased UAE }\end{array}$ & Hyperglycaemia and urinary infections & $\begin{array}{l}{[67,104,} \\
105]\end{array}$ \\
\hline $\begin{array}{l}\text { Multi-target } \\
\text { TKIs }\end{array}$ & $\begin{array}{l}\text { Pazopanib } \\
\text { Sunitinib } \\
\text { Sorafenib } \\
\text { Axitinib }\end{array}$ & $\begin{array}{l}\text { Increased UAE } \\
\text { Nephrotic syndrome }\end{array}$ & $\begin{array}{l}\text { Glomerular endothelial damage; } \\
\text { Podocyte damage }\end{array}$ & $\begin{array}{l}{[67,104} \\
107,108]\end{array}$ \\
\hline Anti-VEGF & $\begin{array}{l}\text { Bevacizumab } \\
\text { Aflibercept }\end{array}$ & Increased UAE & $\begin{array}{l}\text { Glomerular endothelial damage; } \\
\text { Podocyte damage }\end{array}$ & $\begin{array}{l}{[104,107,} \\
108]\end{array}$ \\
\hline ICls & $\begin{array}{l}\text { Ipilimumab } \\
\text { Nivolumab } \\
\text { Pembrolizumab }\end{array}$ & Acute interstitial nephritis & $\begin{array}{l}\text { Delayed hyper-sensitivity with } \\
\text { granulomatous reaction (CD4 }{ }^{+} \mathrm{T} \text { cells } \\
\text { and macrophage activation, gamma- } \\
\text { interferon production); } \\
\text { Podocyte damage }\end{array}$ & [108-110] \\
\hline \multicolumn{5}{|l|}{ Retinopathy } \\
\hline Anti-oestrogen & Tamoxifen & $\begin{array}{l}\text { Retinal exudates and } \\
\text { haemorrhages }\end{array}$ & Retinal thromboembolism & [111-114] \\
\hline $\begin{array}{l}\text { Alkylating } \\
\text { agents }\end{array}$ & $\begin{array}{l}\text { Cisplatin } \\
\text { Carboplatin } \\
\text { Carmustine }\end{array}$ & $\begin{array}{l}\text { Retinal ischaemia and } \\
\text { neovascularization }\end{array}$ & $\begin{array}{l}\text { Retinal thrombosis with vascular } \\
\text { occlusion (phospholipase A2 and } \\
\text { platelet hyperactivation) }\end{array}$ & {$[114,115]$} \\
\hline $\mathrm{ICls}$ & Nivolumab & $\begin{array}{l}\text { Retinal vessels occlusion } \\
\text { Retinal thinning }\end{array}$ & $\begin{array}{l}\text { Autoimmune (abs against retinal } \\
\text { proteins) }\end{array}$ & [116] \\
\hline Oral anti-VEGF & $\begin{array}{l}\text { Pazopanib } \\
\text { Sunitinib } \\
\text { Sorafenib }\end{array}$ & $\begin{array}{l}\text { Retinal vessels bleeding/ } \\
\text { occlusion } \\
\text { Retinal detachment } \\
\text { Macular oedema }\end{array}$ & $\begin{array}{l}\text { Alterations of choroidal vascular } \\
\text { permeability; } \\
\text { Microvascular events (microemboli) }\end{array}$ & [119] \\
\hline $\begin{array}{l}\text { MAPK } \\
\text { inhibitors }\end{array}$ & $\begin{array}{l}\text { Selumetinib } \\
\text { Binimetinib } \\
\text { Pimasertib }\end{array}$ & $\begin{array}{l}\text { Retinal vessels occlusion } \\
\text { Retinal detachment } \\
\text { Subretinal fluid }\end{array}$ & $\begin{array}{l}\text { Alterations of choroidal vascular } \\
\text { permeability; } \\
\text { Autoimmune (abs against retinal } \\
\text { proteins) }\end{array}$ & {$[117-120]$} \\
\hline \multicolumn{5}{|l|}{ Neuropathy } \\
\hline IMIDs & Talidomide & Sensory neuropathy & $\begin{array}{l}\text { Inhibition neurotrophic factors (NGF, } \\
\text { NF-kB); } \\
\text { Reduced angiogenic factors }\end{array}$ & {$[121,122]$} \\
\hline $\begin{array}{l}\text { Proteasome } \\
\text { inhibitor }\end{array}$ & Bortezomib & $\begin{array}{l}\text { Sensory and autonomic } \\
\text { neuropathy }\end{array}$ & $\begin{array}{l}\text { Inhibition neurotrophic factors (NF-kB); } \\
\text { Autoimmune; } \\
\text { miRNA dysregulation (miR-20a, -29b, } \\
-34 a,-128,-181,-342-3 p,-17-92)\end{array}$ & [121-123] \\
\hline \multicolumn{5}{|c|}{ Cardiovascular disease } \\
\hline Anthracyclines & $\begin{array}{l}\text { Doxorubicin } \\
\text { Epirubicin } \\
\text { Idarubicin }\end{array}$ & LV dysfunction/HF & $\begin{array}{l}\text { Increased ROS; } \\
\text { Mitochondrial dysfunction; } \\
\text { Apoptosis }\end{array}$ & $\begin{array}{l}{[124,125} \\
128,129]\end{array}$ \\
\hline $\begin{array}{l}\text { Anti-HER2 } \\
\text { drugs }\end{array}$ & $\begin{array}{l}\text { Trastuzumab Lapatinib } \\
\text { Pertuzumab }\end{array}$ & $\begin{array}{l}\text { LV dysfunction/HF } \\
\text { Hypertension }\end{array}$ & $\begin{array}{l}\text { ErbB2 inhibition with apoptosis of } \\
\text { cardiomyocytes }\end{array}$ & $\begin{array}{l}{[124,125} \\
128,130]\end{array}$ \\
\hline
\end{tabular}


Table 2. Anticancer drugs effects on renal, retinal, neuronal and cardiovascular events (continued)

\begin{tabular}{|c|c|c|c|c|}
\hline Class & Agents & Adverse outcomes & Mechanisms & References \\
\hline $\begin{array}{l}\text { Anti-VEGF and } \\
\text { Multi-target } \\
\text { TKIs }\end{array}$ & $\begin{array}{l}\text { Bevacizumab } \\
\text { Pazopanib Sunitinib } \\
\text { Sorafenib Vandetanib } \\
\text { Regorafenib } \\
\text { Axitinib }\end{array}$ & $\begin{array}{l}\text { LV dysfunction/HF } \\
\text { Hypertension } \\
\text { Myocardial ischemia (rare) } \\
\text { Atherosclerosis }\end{array}$ & $\begin{array}{l}\text { NO-mediated dysregulation of } \\
\text { endothelial homeostasis }\end{array}$ & {$[124,128]$} \\
\hline Anti BCR-ABL1 & $\begin{array}{l}\text { Imatinib Nilotinib } \\
\text { Ponatinib }\end{array}$ & $\begin{array}{l}\text { QTc prolongation } \\
\text { HF }\end{array}$ & $\begin{array}{l}\text { Increased ROS; } \\
\text { Mitochondrial dysfunction; } \\
\text { Cardiomyocytes apoptosis }\end{array}$ & {$[124,128]$} \\
\hline $\mathrm{ICls}$ & $\begin{array}{l}\text { Ipilimumab } \\
\text { Nivolumab } \\
\text { Pembrolizumab }\end{array}$ & $\begin{array}{l}\text { Rare cases of: } \\
\text { - Myocardial fibrosis } \\
\text { - Immune myocarditis } \\
\text { - Cardiomyopathy } \\
\text { - Acute HF } \\
\text { - Lethal myocarditis }\end{array}$ & Immune-mediated damages ${ }^{*}$ & {$[124,132]$} \\
\hline $\begin{array}{l}\text { Proteasome } \\
\text { inhibitors }\end{array}$ & $\begin{array}{l}\text { Bortezomib } \\
\text { Carfilzomib } \\
\text { Ixazomib } \\
\text { Oprozomib }\end{array}$ & $\begin{array}{l}\text { LV dysfunction } \\
\text { Hypertension } \\
\text { Myocardial infarction (rare) } \\
\text { Cardiac arrest (rare) }\end{array}$ & $\begin{array}{l}\text { Increased ROS; } \\
\text { Mitochondrial dysfunction }\end{array}$ & {$[128,131]$} \\
\hline Antimetabolites & $\begin{array}{l}\text { 5-FU } \\
\text { Capecitabine } \\
\text { Gemcitabine }\end{array}$ & Coronary spasms/ischemia & $\begin{array}{l}\text { Increased ROS; } \\
\text { NO reduction; } \\
\text { Increased thrombogenicity }\end{array}$ & {$[127,128]$} \\
\hline Taxanes & $\begin{array}{l}\text { Docetaxel } \\
\text { Paclitaxel }\end{array}$ & $\begin{array}{l}\text { Bradycardia } \\
\text { LV dysfunction } \\
\text { Ischemia }\end{array}$ & $\begin{array}{l}\text { Alteration of tubulin polymerisation and } \\
\text { cell division; } \\
\text { Stimulation of histamine receptors }\end{array}$ & {$[126,128]$} \\
\hline
\end{tabular}

" indicates the uncertainty of the evidence on this item; mTOR: mammalian target of rapamycin; UAE: urinary albumin excretion; TKIs: tyrosine kinase inhibitors; VEGF: vascular endothelial growth factor; ICls: immune checkpoint inhibitors; Abs: antibodies; MAPK: mitogen-activated protein kinase; IMIDs: immunomodulatory drugs; NGF: nerve growth factor; NF-kB: nuclear factor kappa-light-chain-enhancer of activated B cells; miRNA: microRNA; LV: left ventricular; HF: heart failure; ROS: reactive oxygen species; HER2: human epidermal growth factor receptor 2; NO: nitric oxide; BCR-ABL: breakpoint cluster region Abelson gene; QTc: corrected QT; 5-FU: 5-Fluorouracil

Acute interstitial nephritis was described in patients treated with ICIs with occurrence within 3-12 months [108-110] (Table 2).

These findings suggest the need for a clinical (e.g., hydration status, arterial pressure, etc.) and laboratory (creatinine, electrolytes, and urinary protein) monitoring of these patients, in particular in those with nausea and vomiting, to early detect renal AEs [27, 108].

\section{Retinopathy}

Very limited evidence is available on the influence of anticancer drugs on diabetes retinopathy (Table 2). The $6 \%$ of T2D and cancer patients experienced the onset or progression of retinopathy in the six months after chemotherapy, but a correlation with specific anticancer molecules or protocols has not been established [67].

Tamoxifen, an anti-oestrogen widely used in breast cancer, is associated with the occurrence of retinal exudates and haemorrhages [111-113] (Table 2). Some reports described sporadic cases of different types of retinal injury induced by various anticancer drugs (alkylating agents, ICIs, MAP kinase inhibitors, and antiVEGF) [114-120] (Table 2).

\section{Neuropathy}

Bortezomib and thalidomide, both used in the treatment of multiple myeloma, can affect the peripheral nervous system by means of poorly understood mechanisms, probably involving the inhibition of angiogenic 
and neurotrophic factors essential for the nervous system [121] (Table 2). Bortezomib causes neuropathy in up to $40 \%$ of patients [122]. Both sensory (paraesthesia, pain) and autonomic (postural dizziness, syncope, diarrhoea, impotence, and urinary disturbances) neuropathic symptoms are described [123]. These AEs are often reversible within six months since bortezomib withdrawal and their incidence decreases with subcutaneous and once-weekly administration [121]. The 70\% of patients with prolonged exposure $(12$ months) to thalidomide experienced bilateral and symmetrical neuropathic sensory, and rarely, autonomic or motor disorders [122] (Table 2).

\section{Cardiovascular disease}

Both conventional (e.g., anthracyclines, taxanes, and antimetabolites) and novel biological targeted cancer therapies can induce cardiovascular AEs, such as hypertension, QT interval prolongation, left ventricular dysfunction, and heart failure [124-127] (Table 2). These fearful and potentially life-threatening AEs can be irreversible, resulting from classical cytolytic cancer therapies, or reversible, more often related to novel biological therapies [128].

Anthracyclines (doxorubicin, epirubicin, and idarubicin), used both in solid and haematological cancers, are associated with left ventricular dysfunction and heart failure in up to $20 \%$ of treated patients. The acute, early onset cardiotoxicity of doxorubicin is dose dependent (doses $\geq 450 \mathrm{mg} / \mathrm{m}^{2}$ ) and mainly mediated by reactive oxygen species, while late onset AEs are dose-independent and reported in half of the patients within six years $[124,129]$ (Table 2).

Trastuzumab and TKIs targeting the human epidermal growth factor receptor 2 (HER-2) can lead to hypertension and reduced heart function that, unlike anthracycline-dependent cardiotoxicity, are often reversible [130] (Table 2). A high incidence of hypertension, left ventricular dysfunction, and atherosclerosis was also reported in patients treated with anti-VEGF, multi-target TKIs therapies, and proteasome inhibitors $[124,131]$ (Table 2).

Although infrequently, cancer immunotherapies could cause heart disease. ICIs are related to cardiomyopathy, myocardial fibrosis, myocarditis, acute heart failure, and lethal myocarditis [124] (Table 2). The risk for ICIs-related cardiovascular AEs increases when these antibodies are used in combination (e.g., ipilimumab and nivolumab) [132].

The early detection of cardiovascular complications of anticancer drugs is mandatory to avoid severe and/ or permanent injuries. The use of biomarkers (troponin-I, brain-type natriuretic peptide, and N-terminal-proBNP) and imaging techniques (echocardiography, cardiac magnetic resonance) could be useful, although no specific recommendations or guidelines are available [124]. Dexrazoxane, interfering with iron-dependent redox mechanisms, is useful to reduce acute and chronic cardiotoxicity of anthracyclines [133]. However, its use is limited to urgent cases because of the relevant risk of bone marrow suppression [134]. Beta-blockers, angiotensin-converting enzyme inhibitor, angiotensin inhibitors, and mineralocorticoid receptor antagonists gave encouraging results in preventing cardiac injury related to anticancer therapies [135].

Among traditional cardiovascular risk factors, dyslipidaemia should not be forgotten. A close lipid monitoring is necessary, mainly in patients treated with drugs already known to increase lipid level such as those targeting the PI3K-Akt-mTOR pathway, GCs, and anti-androgens [67, 86, 136]. Specific therapies for dyslipidaemia should be evaluated keeping in mind the potential side effects (e.g., cramps in statins users), drug-drug interactions, and patients' life expectancy [9]. Pravastatin is recommended as first line pharmacological therapy for low density lipoprotein (LDL) reduction, while simvastatin and atorvastatin are contraindicated, because of their interferences with drugs metabolised by cytochrome P450 system [86, 136].

\section{Caution in the use of therapies: drug-drug interactions}

The $30 \%$ of all cancer patients are at risk for drug-drug interferences $[137,138]$. Patients affected by both cancer and T2D are often treated with multiple drugs, thus, physicians have to consider the risk of drug-drug interferences, potential cause of AEs, increased or decreased effect of both antineoplastic and diabetes agents, and reduced patients' quality of life [139]. Most diabetes and cancer drugs have a liver metabolism in the 
cytochrome $\mathrm{P} 450$ system. Chemotherapeutic agents, but also several drugs currently used in cancer patients (antibiotics, antifungals, non-steroidal anti-inflammatory), interact with the cytochrome P450 system, increasing the exposure of diabetes drugs and the risk of AEs, in particular hypoglycaemia $[9,27,140]$. On the contrary, multidrug therapies with inhibitors or inducers of the cytochrome P450 may affect anticancer drug concentration influencing their safety and efficacy. An example of mutual influence between diabetes and anticancer drugs due to the cytochrome P450 metabolism is represented by the interaction of TKIs with both insulin secretagogues (glibenclamide and metiglinides) and TZDs [141, 142].

Many T2D patients are treated for dyslipidaemia before cancer diagnosis and some anticancer drugs (selective oestrogen receptor modulators, aromatase inhibitors, GnRH analogues, anti-androgens, mTOR pathway inhibitors, and high-dose GCs) can worsen the lipid profile requiring a specific therapy $[67,75,76$, $86,136]$. It is reported a potential harmful interaction between lipid-lowering agents, fibrates, and inhibitor of the mTOR. In particular, in oncologic patients treated with everolimus, the administration of simvastatin or lovastatin should be avoided and the use of other statins (rosuvastatin, atorvastatin, fluvastatin, or pravastatin) is preferred [142].

Considering the high prevalence of drug-drug interactions in patients with diabetes and cancer and the consequent risk for AEs, a systematic therapy review before and during anticancer treatment, possibly supported by a clinical pharmacologist, could be useful and cost-effective $[137,138]$.

\section{Conclusion: what do we need?}

Despite the growing number of patients having both diabetes and cancer, their clinical management still represents a challenge for physicians. The lack of guidelines or standardised protocols is a major critical point. In fact, only few data, derived from retrospective, observational studies, are available, and many critical issues require prospective, better-designed studies, to be settled.

The appropriate level of glycaemic targets, the influence of anticancer drugs on glucose profile and vascular complications, drugs interactions, and the often forgotten patients' nutritional status are just some of the clinical aspects whose knowledge needs to be improved [143]. The glycaemic targets, mainly oriented on the short-term complications and reduction of hyperglycaemic osmotic effects, are certainly the Achilles heel of the challenging management of patients with diabetes and cancer, and need a revision. The assessment of patient's life expectancy and quality of life should be constantly updated to direct the efforts of all the involved specialists and achieve the best results. Prospective, targeted studies could be useful to identify clinical and easily available predictors (e.g., gender, age, diabetes duration, BMI, etc.) of the described AEs. This would help the early identification of patients particularly at risk who require close monitoring of these AEs.

The clinical complexity of patients having both diabetes and cancer makes necessary a patient-centred, personalised approach. The multidisciplinary team (MDT) involves many healthcare professionals who take all treatment options into consideration and collaboratively develop a tailored treatment plan for each patient (Figure 1). Currently, this strategy is worldwide considered as a standard for the management of patients with cancer and it is increasingly practiced through periodic, usually weekly, meetings. MDT is already a reality in the main medical centres with a huge volume of patients, while it is less practiced in more peripheral areas with fewer patients. Accordingly, the management of these patients is uncoordinated and too compartmentalised with a consequent reduction of both the patients' level of assistance and quality of life, the latter already affected by the burden of these diseases.

Diabetologists, oncologists but also cardiologists, nephrologists, ophthalmologists, neurologists, nutritionists, psychologists, and nurses, should work simultaneously in a coordinated "oncometabolic" team [144] (Figure 1). A similar dedicated clinical pathway could lead to optimise human and economic resources and, mainly, to achieve the best clinical results of these frail patients affected by diabetes and cancer. 


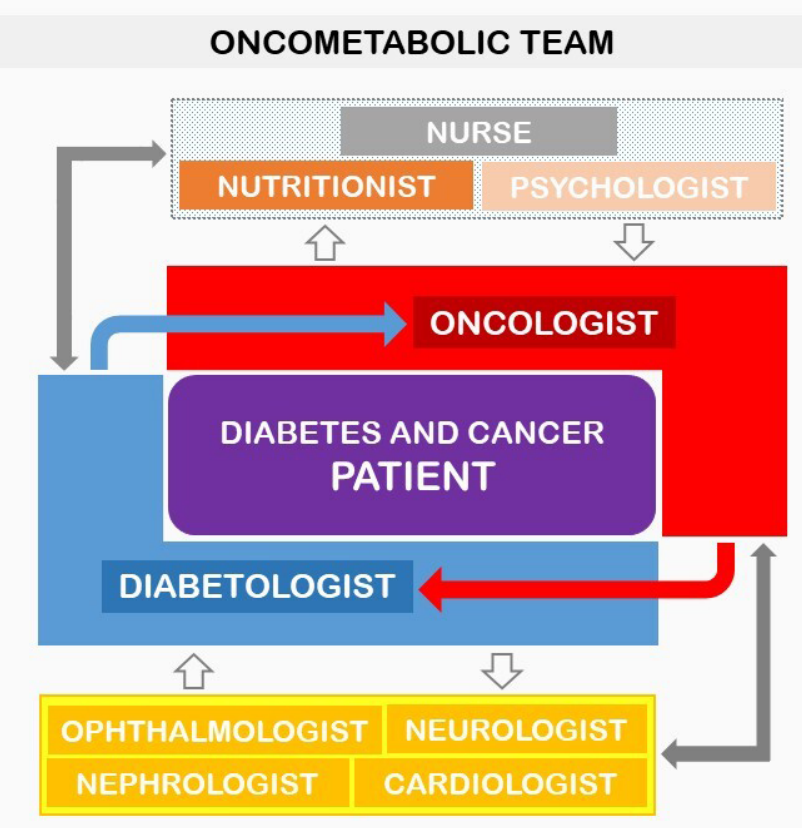

Figure 1. Schematic representation of the oncometabolic network for the care of patients with diabetes and cancer. Diabetologist and oncologist, the leading figures of the oncometabolic, multidisciplinary team (central part of the figure), collaborate to address the diagnostic and therapeutic course of these patients and manage the connection with the other specialists involved (top and bottom of the figure)

\section{Abbreviations}

AEs: adverse events

DPP4-I: dipeptidyl peptidase-4 inhibitors

GCs: glucocorticoids

GLP1-RA: glucagon-like peptide-1 receptor agonists

GnRH: gonadotropin releasing hormone

HbA1c: glycated haemoglobin

ICIs: immune checkpoint inhibitors

IP/S: insulin production/secretion

MDT: multidisciplinary teams

mTOR: mammalian target of rapamycin

NETs: neuroendocrine tumours

PD-1: programmed cell death-1

PDL-1: programmed cell death ligand-1

PI3K: phosphatidylinositol-3-kinase

SGLT2-I: sodium glucose transporter-2 inhibitors

SST: somatostatin

SST-A: somatostatin analogues

SSTR: somatostatin receptors

T2D: type 2 diabetes

TKIs: tyrosine-kinase inhibitors

TZDs: thiazolidinediones

VEGF: vascular endothelial growth factor 


\section{Declarations}

Acknowledgments

The authors gratefully acknowledge professor Giuliana Arcidiacono, English and Anglo-American language PhD., University of Catania, for the language revision of the manuscript.

\section{Author contributions}

AM wrote the first draft of the manuscript; PV, FM, RV, and LS wrote sections of the manuscript. All authors contributed to manuscript revision, read and approved the submitted version.

\section{Conflicts of interest}

Not applicable.

\section{Ethical approval}

Not applicable.

\section{Consent to participate}

Not applicable.

\section{Consent to publication}

Not applicable.

\section{Availability of data and materials}

Not applicable.

\section{Funding}

Not applicable.

\section{Copyright}

(C) The Author(s) 2020.

\section{References}

1. Cho NH, Shaw JE, Karuranga S, Huang Y, da Rocha Fernandes JD, Ohlrogge AW, et al. IDF diabetes atlas: global estimates of diabetes prevalence for 2017 and projections for 2045. Diabetes Res Clin Pract. 2018;138:271-81.

2. Ferlay J, Colombet M, Soerjomataram I, Mathers C, Parkin DM, Piñeros M, etal. Estimating the global cancer incidence and mortality in 2018: GLOBOCAN sources and methods. Int J Cancer. 2019;144:1941-53.

3. Cignarelli A, Genchi VA, Caruso I, Natalicchio A, Perrini S, Laviola L, et al. Diabetes and cancer: pathophysiological fundamentals of a 'dangerous affair'. Diabetes Res Clin Pract. 2018;143:378-88.

4. Vella V, Milluzzo A, Scalisi NM, Vigneri P, Sciacca L. Insulin Receptor Isoforms in Cancer. Int J Mol Sci. 2018;19:3615.

5. Belfiore A, Malaguarnera R, Vella V, Lawrence MC, Sciacca L, Frasca F, et al. Insulin receptor isoforms in physiology and disease: an updated view. Endocr Rev. 2017;38:379-431.

6. Sciacca L, Vigneri R, Tumminia A, Frasca F, Squatrito S, Frittitta L, et al. Clinical and molecular mechanisms favouring cancer initiation and progression in diabetic patients. Nutr Metab Cardiovasc Dis. 2013;23:808-15.

7. Sciacca L, Cassarino MF, Genua M, Vigneri P, Pennisi MG, Malandrino P, et al. Biological effects of insulin and its analogs on cancer cells with different insulin family receptor expression. J Cell Physiol. 2014;229:1817-21. 
8. Sciacca L, Scalisi NM, Cassarino MF, Milluzzo A, Tumminia A, Sciacchitano S, et al. Different effects of the insulin receptor isoforms on 32D cell growth and differentiation. J Diabetes Endocrinol Metab Disord. 2017:1-9.

9. Gallo M, Muscogiuri G, Felicetti F, Faggiano A, Trimarchi F, Arvat E, et al. Adverse glycaemic effects of cancer therapy: indications for a rational approach to cancer patients with diabetes. Metabolism. 2018;78:141-54.

10. Giovannucci E, Harlan DM, Archer MC, Bergenstal RM, Gapstur SM, Habel LA, et al. Diabetes and cancer: a consensus report. Diabetes Care. 2010;33:1674-85.

11. Pearson-Stuttard J, Zhou B, Kontis V, Bentham J, Gunter MJ, Ezzati M. Worldwide burden of cancer attributable to diabetes and high body-mass index: a comparative risk assessment. Lancet Diabetes Endocrinol. 2018;6:95-104.

12. Barone BB, Yeh HC, Snyder CF, Peairs KS, Stein KB, Derr RL, et al. Long-term all-cause mortality in cancer patients with preexisting diabetes mellitus: a systematic review and meta-analysis. JAMA. 2008;300:2754-64.

13. Zhou XH, Qiao Q, Zethelius B, Pyörälä K, Söderberg S, Pajak A, et al. Diabetes, prediabetes and cancer mortality. Diabetologia. 2010;53:1867-76.

14. Barone BB, Yeh HC, Snyder CF, Peairs KS, Stein KB, Derr RL, et al. Postoperative mortality in cancer patients with preexisting diabetes: systematic review and meta-analysis. Diabetes Care. 2010;33:931-9.

15. Lipscombe LL, Chan WW, Yun L, Austin PC, Anderson GM, Rochon PA. Incidence of diabetes among postmenopausal breast cancer survivors. Diabetologia. 2013;56:476-83.

16. De Bruijn KM, van Eijck CH. New-onset diabetes after distal pancreatectomy: a systematic review. Ann Surg. 2015;261:854-61.

17. Singh S, Earle CC, Bae SJ, Fischer HD, Yun L, Austin PC, et al. Incidence of diabetes in colorectal cancer survivors. J Natl Cancer Inst. 2016;108:djv402.

18. Hwangbo Y, Kang D, Kang M, Kim S, Lee EK, Kim YA, et al. Incidence of diabetes after cancer development: a Korean national cohort study. JAMA Oncol. 2018;4:1099-105.

19. Zanders MM, Haak HR, van Herk-Sukel MP, van de Poll-Franse LV, Johnson JA. Impact of cancer on adherence to glucose-lowering drug treatment in individuals with diabetes. Diabetologia. 201;58:951-60.

20. Pinheiro LC, Soroka O, Kern LM, Leonard JP, Safford MM. Diabetes care management patterns before and after a cancer diagnosis: a SEER-Medicare matched cohort study. Cancer. 2020;126:1727-35.

21. Handelsman Y, Leroith D, Bloomgarden ZT, Dagogo-Jack S, Einhorn D, Garber AJ, et al. Diabetes and cancer--an AACE/ACE consensus statement. Endocr Pract. 2013;19:675-93.

22. Weiser MA, Cabanillas ME, Konopleva M, Thomas DA, Pierce SA, Escalante CP, et al. Relation between the duration of remission and hyperglycemia during induction chemotherapy for acute lymphocytic leukemia with a hyperfractionated cyclophosphamide, vincristine, doxorubicin, and dexamethasone/ methotrexate-cytarabine regimen. Cancer. 2004;100:1179-85.

23. Currie CJ, Poole CD, Jenkins-Jones S, Gale EA, Johnson JA, Morgan CL. Mortality after incident cancer in people with and without type 2 diabetes: impact of metformin on survival. Diabetes Care. 2012;35:299-304.

24. Lee W, Yoon YS, Han HS, Cho JY, Choi Y, Jang JY, et al. Prognostic relevance of preoperative diabetes mellitus and the degree of hyperglycemia on the outcomes of resected pancreatic ductal adenocarcinoma. J Surg Oncol. 2016;113:203-8.

25. Shi HJ, Jin C, Fu DL. Impact of postoperative glycemic control and nutritional status on clinical outcomes after total pancreatectomy. World J Gastroenterol. 2017;23:265-274.

26. Lee H, Kuk H, Byun SS, Lee SE, Hong SK. Preoperative glycemic control status as a significant predictor of biochemical recurrence in prostate cancer patients after radical prostatectomy. PLoS One. 2015;10:e0124761. 
27. Chowdhury TA, Jacob P. Challenges in the management of people with diabetes and cancer. Diabet Med. 2019;36:795-802.

28. Associazione Medici Diabetologi (AMD) - Società Italiana di Diabetologia (SID). Standard italiani per la cura del diabete mellito 2018. Available from: http://www.siditalia.it/clinica/standard-di-cura-amdsid. [Last accessed on 20 March 2020].

29. Fracchia AC, Ragni A, D’Angelo V, Nervo A, Arvat E, Gallo M. Gestione clinica del diabete nel paziente oncologico: esperienza di un centro di riferimento terziario. JAMD. 2019;21:278-86. Italian.

30. McCoubrie R, Jeffrey D, Paton C, Dawes L. Managing diabetes mellitus in patients with advanced cancer: a case note audit and guidelines. Eur J Cancer Care. 2005;14:244-8.

31. Gloyn AL, Drucker DJ. Precision medicine in the management of type 2 diabetes. Lancet Diabetes Endocrinol. 2018;6:891-900.

32. Jacob P, Chowdhury TA. Management of diabetes in patients with cancer. QJM. 2015;108:443-8.

33. Meneghini L, Atkin SL, Gough SCL, Raz I, Blonde L, Shestakova M, et al. The efficacy and safety of insulin degludec given in variable once-daily dosing intervals compared with insulin glargine and insulin degludec dosed at the same time daily: a 26-week, randomized, open-label, parallel-group, treat-totarget trial in individuals with type 2 diabetes. Diabetes Care 2013;36:858-64.

34. Sciacca L, Vella V, Frittitta L, Tumminia A, Manzella L, Squatrito S, et al. Long-acting insulin analogs and cancer. Nutr Metab Cardiovasc Dis. 2018;28:436-43.

35. Wu JW, Filion KB, Azoulay L, Doll MK, Suissa S. Effect of long-acting insulin analogs on the risk of cancer: a systematic review of observational studies. Diabetes Care. 2016;39:486-94.

36. ORIGIN Trial Investigators; Gerstein HC, Bosch J, Dagenais GR, Díaz R, Jung H, Maggioni AP, et al. Basal insulin and cardiovascular and other outcomes in dysglycemia. N Engl J Med. 2012;367:319-28.

37. Andersen SE, Christensen M. Hypoglycaemia when adding sulphonylurea to metformin: a systematic review and network meta-analysis. Br J Clin Pharmacol. 2016;82:1291-302.

38. Chan SP, Colagiuri S. Systematic review and meta-analysis of the efficacy and hypoglycemic safety of gliclazide versus other insulinotropic agents. Diabetes Res Clin Pract. 2015;110:75-81.

39. Vigneri R, Sciacca L. Diabetes and Cancer. In: Bonora E, DeFronzo RA, editors. Endocrinology: Diabetes Complications, Comorbidities and Related Disorders. Switzerland: Springer; 2018. pp. 377-410.

40. Rizos CV, Elisaf MS. Metformin and cancer. Eur J Pharmacol. 2013;705:96-108.

41. Libby G, Donnelly LA, Donnan PT, Alessi DR, Morris AD, Evans JMM. New users of metformin are at low risk of incident cancer: a cohort study among people with type 2 diabetes. Diabetes Care. 2009;32:1620-5.

42. Yin M, Zhou J, Gorak EJ, Quddus F. Metformin is associated with survival benefit in cancer patients with concurrent type 2 diabetes: a systematic review and meta-analysis. Oncologist. 2013;18:1248-55.

43. Cheung KS, Chan EW, Chen L, Seto WK, Wong ICK, Leung WK. Diabetes increases risk of gastric cancer after Helicobacter pylori eradication: a territory-wide study with propensity score analysis. Diabetes Care. 2019;42:1769-75.

44. Rao M, Gao C, Guo M, Law BYK, Xu Y. Effects of metformin treatment on radiotherapy efficacy in patients with cancer and diabetes: a systematic review and meta-analysis. Cancer Manag Res. 2018;10:4881-90.

45. Suissa S, Azoulay L. Metformin and the risk of cancer: time-related biases in observational studies. Diabetes Care. 2012;35:2665-73.

46. Tseng CH. A review on thiazolidinediones and bladder cancer in human studies. J Environ Sci Health C Environ Carcinog Ecotoxicol Rev. 2014;32:1-45.

47. Tuccori M, Filion KB, Yin H, Yu OH, Platt RW, Azoulay L. Pioglitazone use and risk of bladder cancer: population based cohort study. BMJ. 2016;352:i1541. 
48. Lewis JD, Ferrara A, Peng T, Hedderson M, Bilker WB, Quesenberry CP Jr, et al. Risk of bladder cancer among diabetic patients treated with pioglitazone: interim report of a longitudinal cohort study. Diabetes Care. 2011;34:916-22.

49. Lewis JD, Habel LA, Quesenberry CP, Strom BL, Peng T, Hedderson MM, et al. Pioglitazone use and risk of bladder cancer and other common cancers in persons with diabetes. JAMA. 2015;314:265-77.

50. Monami M, Dicembrini I, Mannucci E. Thiazolidinediones and cancer: results of a meta-analysis of randomized clinical trials. Acta Diabetol. 2014;51:91-101.

51. Tseng C, Lee K, Tseng F. An updated review on cancer risk associated with incretin mimetics and enhancers. J Environ Sci Health C Environ Carcinog Ecotoxicol Rev. 2015;33:67-124.

52. Labuzek K, Kozłowski M, Szkudłapski D, Sikorska P, Kozłowska M, Okopień B. Incretin-based therapies in the treatment of type 2 diabetes-more than meets the eye? Eur J Intern Med. 2013;24:207-12.

53. Vangoitsenhoven R, Mathieu C, Van der Schueren B. GLP1 and cancer: friend or foe? Endocr Relat Cancer. 2012;19:F77-88.

54. Dankner R, Roth J. More recent, better designed studies have weakened links between antidiabetes medications and cancer risk. Diabet Med. 2020;37:194-202.

55. Monami M, Nreu B, Scatena A, Cresci B, Andreozzi F, Sesti G, et al. Safety issues with glucagon-like peptide-1 receptor agonists (pancreatitis, pancreatic cancer and cholelithiasis): data from randomized controlled trials. Diabetes Obes Metab. 2017;19:1233-41.

56. Dicembrini I, Nreu B, Montereggi C, Mannucci E, Monami M. Risk of cancer in patients treated with dipeptidyl peptidase- 4 inhibitors: an extensive meta-analysis of randomized controlled trials. Acta Diabetol. 2020;57:689-96.

57. Bishnoi R, Hong YR, Shah C, Ali A, Skelton WP 4th, Huo J, et al. Dipeptidyl peptidase 4 inhibitors as novel agents in improving survival in diabetic patients with colorectal cancer and lung cancer: a Surveillance Epidemiology and Endpoint Research Medicare study. Cancer. Med. 2019;8:3918-27.

58. Noh Y, Jeon SM, Shin S. Association between glucose-lowering treatment and cancer metastasis among patients with preexisting type 2 diabetes and incident malignancy. Int J Cancer. 2019;144:1530-9.

59. Dicembrini I, Nreu B, Mannucci E, Monami M. Sodium-glucose co-transporter-2 (SGLT-2) inhibitors and cancer: a meta-analysis of randomized controlled trials. Diabetes Obes Metab. 2019;21:1871-7.

60. Tang H, Dai Q Shi W, Zhai S, Song Y, Han J. SGLT2 inhibitors and risk of cancer in type 2 diabetes: a systematic review and meta-analysis of randomised controlled trials. Diabetologia. 2017;60:1862-72.

61. Nasiri AR, Rodrigues MR, Li Z, Leitner BP, Perry RJ. SGLT2 inhibition slows tumor growth in mice by reversing hyperinsulinemia. Cancer Metab. 2019;7:10.

62. Jojima T, Wakamatsu S, Kase M, Iijima T, Maejima Y, Shimomura K, et al. The SGLT2 inhibitor canagliflozin prevents carcinogenesis in a mouse model of diabetes and non-alcoholic steatohepatitis-related hepatocarcinogenesis: association with SGLT2 expression in hepatocellular carcinoma. Int J Mol Sci. 2019;20:5237.

63. Kaji K, Nishimura N, Seki K, Sato S, Saikawa S, Nakanishi K, et al. Sodium glucose cotransporter 2 inhibitor canagliflozin attenuates liver cancer cell growth and angiogenic activity by inhibiting glucose uptake. Int J Cancer. 2018;142:1712-22.

64. Villani LA, Smith BK, Marcinko K, Ford RJ, Broadfield LA, Green AE, et al. The diabetes medication Canagliflozin reduces cancer cell proliferation by inhibiting mitochondrial complex-I supported respiration. Mol Metab. 2016;5:1048-56.

65. Hung MH, Chen YL, Chen LJ, Chu PY, Hsieh FS, Tsai MH, et al. Canagliflozin inhibits growth of hepatocellular carcinoma via blocking glucose-influx-induced $\beta$-catenin activation. Cell Death Dis. 2019;10:420.

66. Hershey DS, Bryant AL, Olausson J, Davis ED, Brady VJ, Hammer M. Hyperglycemic-inducing neoadjuvant agents used in treatment of solid tumors: a review of the literature. Oncol Nurs Forum. 2014;41:E343-54. 
67. Milluzzo A, Tumminia A, Vella V, Gianì F, Manzella L, Frittitta L, et al. Short-term adverse effects of anticancer drugs in patients with type 2 diabetes. J Chemother. 2019;31:150-9.

68. Leak A, Davis ED, Houchin LB, Mabrey M. Diabetes management and self-care education for hospitalized patients with cancer. Clin J Oncol Nurs. 2009;13:205-10.

69. Hershey DS, Hession S. Chemotherapy and glycemic control in patients with type 2 diabetes and cancer: a comparative case analysis. Asia Pac J Oncol Nurs. 2017;4:224-32.

70. Pettit S, Cresta E, Winkley K, Purssell E, Armes J. Glycaemic control in people with type 2 diabetes mellitus during and after cancer treatment: a systematic review and meta-analysis. PLoS One. 2017;12:e0176941.

71. Ariaans G, de Jong S, Gietema JA, Lefrandt JD, de Vries EG, Jalving M. Cancer-drug induced insulin resistance: innocent bystander or unusual suspect. Cancer Treat Rev. 2015;41:376-84.

72. Shariff AI, Syed S, Shelby RA, Force J, Clarke JM, D'Alessio D, et al. Novel cancer therapies and their association with diabetes. J Mol Endocrinol. 2019;62:R187-99.

73. Keating NL, Liu PH, O'Malley AJ, Freedland SJ, Smith MR. Androgen-deprivation therapy and diabetes control among diabetic men with prostate cancer. Eur Urol. 2014;65:816-24.

74. Vigneri P, Frasca F, Sciacca L, Pandini G, Vigneri R. Diabetes and cancer. Endocr Relat Cancer. 2009;16:1103-23.

75. Saylor PJ, Smith MR. Metabolic complications of androgen deprivation therapy for prostate cancer. J Urol. 2013;189 Suppl 1:S34-42.

76. Collier A, Ghosh S, McGlynn B, Hollins G. Prostate cancer, androgen deprivation therapy, obesity, the metabolic syndrome, type 2 diabetes, and cardiovascular disease: a review. Am J Clin Oncol. 2012;35:504-9.

77. Smith MR, Finkelstein JS, McGovern FJ, Zietman AL, Fallon MA, Schoenfeld DA, et al. Changes in body composition during androgen deprivation therapy for prostate cancer. J Clin Endocrinol Metab. 2002;87:599-603.

78. Derweesh IH, Diblasio CJ, Kincade MC, Malcolm JB, Lamar KD, Patterson AL, et al. Risk of new-onset diabetes mellitus and worsening glycaemic variables for established diabetes in men undergoing androgen-deprivation therapy for prostate cancer. BJU Int. 2007;100:1060-5.

79. Hwang JL, Weiss RE. Steroid-induced diabetes: a clinical and molecular approach to understanding and treatment. Diabetes Metab Res Rev. 2014;30:96-102.

80. Kasayama S, Tanaka T, Hashimoto K, Koga M, Kawase I. Efficacy of glimepiride for the treatment of diabetes occurring during glucocorticoid therapy. Diabetes Care. 2002;25:2359-60.

81. Hans P, Vanthuyne A, Dewandre PY, Brichant JF, Bonhomme V. Blood glucose concentration profile after $10 \mathrm{mg}$ dexamethasone in non-diabetic and type 2 diabetic patients undergoing abdominal surgery. $\mathrm{Br} \mathrm{J}$ Anaesth. 2006;97:164-70.

82. Tamez-Pérez HE, Quintanilla-Flores DL, Rodríguez-Gutiérrez R, González-González JG, Tamez-Peña AL. Steroid hyperglycemia: prevalence, early detection and therapeutic recommendations: a narrative review. World J Diabetes. 2015;6:1073-81.

83. Management of Hyperglycaemia and Steroid (Glucocorticoid) Therapy. Available from: http://www. diabetologists-abcd.org.uk/JBDS/JBDS_IP_Steroids.pdf. [Last accessed on 20 March 2020].

84. Tanimura J, Nakagawa H, Tanaka T, Kikuchi A, Osada S, Tanaka Y, et al. The clinical course and potential underlying mechanisms of everolimus-induced hyperglycemia. Endocr J. 2019;66:615-20.

85. Morviducci L, Rota F, Rizza L, Di Giacinto P, Ramponi S, Nardone MR, et al. Everolimus is a new anticancer molecule: Metabolic side effects as lipid disorders and hyperglycemia. Diabetes Res Clin Pract. 2018;143:428-31.

86. Sivendran S, Agarwal N, Gartrell B, Ying J, Boucherc KM, Choueiri TK, et al. Metabolic complications with the use of mTOR inhibitors for cancer therapy. Cancer Treat Rev. 2014; 40:190-6. 
87. Araki M, Flechner SM, Ismail HR, Flechner LM, Zhou L, Derweesh IH, et al. Posttransplant diabetes mellitus in kidney transplant recipients receiving calcineurin or mTOR inhibitor drugs. Transplantation. 2006;81:335-41.

88. Paplomata E, Zelnak A, O'Regan R. Everolimus: side effect profile and management of toxicities in breast cancer. Breast Cancer Res Treat. 2013;140:453-62.

89. Akturk HK, Kahramangil D, Sarwal A, Hoffecker L, Murad MH, Michels AW. Immune checkpoint inhibitorinduced Type 1 diabetes: a systematic review and meta-analysis. Diabet Med. 2019;36:1075-81.

90. Liu J, Zhou H, Zhang Y, Fang W, Yang Y, Huang Y, et al. Reporting of immune checkpoint inhibitor therapyassociated diabetes, 2015-2019. Diabetes Care. 2020;43:e79-80.

91. Monami M, Naletto L, Nreu B, Dicembrini I, Sesti G, Mannucci E. Immune checkpoints inhibitors and hyperglycemia: a meta-analysis of randomized controlled trials. Diabetes Res Clin Pract. 2020;162:108115.

92. Singh P, Alex JM, Bast F. Insulin receptor (IR) and insulin-like growth factor receptor 1 (IGF-1R) signaling systems: novel treatment strategies for cancer. Med Oncol. 2014;31:805.

93. Muhammad A, van der Lely AJ, Delhanty PJD, Dallenga AHG, Haitsma IK, Janssen JAMJL, et al. Efficacy and safety of switching to pasireotide in patients with acromegaly controlled with pegvisomant and firstgeneration somatostatin analogues (PAPE Study). J Clin Endocrinol Metab. 2018;103:586-95.

94. Schmid HA, Schoeffter P. Functional activity of the multiligand analog SOM230 at human recombinant somatostatin receptor subtypes supports its usefulness in neuroendocrine tumors. Neuroendocrinology. 2004;80 Suppl 1:47-50.

95. Yoshida H, Imamura T, Saito AM, Takahashi Y, Suenobu S, Hasegawa D, et al; Japan Association of Childhood Leukemia Study. Protracted administration of $L$-asparaginase in maintenance phase is the risk factor for hyperglycemia in older patients with pediatric acute lymphoblastic leukemia. PLoS One. 2015; 10:e136428.

96. Flores-Calderón J, Exiga-Gonzaléz E, Morán-Villota S, Martín-Trejo J, Yamamoto-Nagano A. Acute pancreatitis in children with acute lymphoblastic leukemia treated with $L$-asparaginase. J Pediatr Hematol Oncol. 2009;31:790-3.

97. Lee YJ, Doliny P, Gomez-Fernandez C, Powell J, Reis I, Hurley J. Docetaxel and cisplatin as primary chemotherapy for treatment of locally advanced breast cancers. Clin Breast Cancer. 2004;5:371-6.

98. Okabe $\mathrm{S}$, Ishikawa $\mathrm{T}$, Tanami $\mathrm{H}$, Kuwabara $\mathrm{H}$, Fukahara $\mathrm{T}$, Udagawa $\mathrm{M}$, et al. Investigation into the usefulness and adverse events of CDDP, 5-fU and dl-leucovorin (PFL-therapy) for advanced colorectal cancer. J Med Dent Sci. 2002;49:77-84.

99. Fury MG, Sherman E, Haque S, Korte S, Lisa D, Shen R, et al. A phase I study of daily everolimus plus low-dose weekly cisplatin for patients with advanced solid tumors. Cancer Chemother Pharmacol. 2012;69:591-8.

100. Infante JR, Yardley DA, Burris HA 3rd, Greco FA, Farley CP, Webb C, et al. Phase II trial of weekly docetaxel, vinorelbine, and trastuzumab in the first-line treatment of patients with HER2-positive metastatic breast cancer. Clin Breast Cancer. 2009;9:23-8.

101. Feng JP, Yuan XL, Li M, Fang J, Xie T, Zhou Y, et al. Secondary diabetes associated with 5-fluorouracilbased chemotherapy regimens in non-diabetic patients with colorectal cancer: results from a singlecentre cohort study. Colorectal Dis. 2013;15:27-33.

102. Fedeli U, Zoppini G, Gennaro N, Saugo M. Diabetes and cancer mortality: a multifaceted association. Diabetes Res Clin Pract. 2014;106:e86-9.

103. Richardson LC, Pollack LA. Therapy insight: influence of type 2 diabetes on the development, treatment and outcomes of cancer. Nat Clin Prac Oncol. 2005;2:48-53.

104. Eisen T, Sternberg CN, Robert C, Mulders P, Pyle L, Zbinden S, et al. Targeted therapies for renal cell carcinoma: review of adverse event management strategies. J Natl Cancer Inst. 2012;104:93-113. 
105. Kajiwara M, Masuda S. Role of mTOR inhibitors in kidney disease. Int J Mol Sci. 2016;17:975.

106. Schena FP, Gesualdo L. Pathogenetic mechanisms of diabetic nephropathy. J Am Soc Nephrol. 2005;16 Suppl 1:S30-3.

107. Izzedine H, Escudier B, Lhomme C, Pautier P, Rouvier P, Gueutin V, et al. Kidney diseases associated with anti-vascular endothelial growth factor (VEGF): an 8-year observational study at a single center. Medicine (Baltimore). 2014;93:333-9.

108. Jhaveri KD, Wanchoo R, Sakhiya V, Ross DW, Fishbane S. Adverse renal effects of novel molecular oncologic targeted therapies: a narrative review. Kidney Int Rep. 2016;2:108-23.

109. Thajudeen B, Madhrira M, Bracamonte E, Cranmer LD. Ipilimumab granulomatous interstitial nephritis. Am J Ther. 2015;22:e84-7.

110. Shirali AC, Perazella MA, Gettinger S. Association of acute interstitial nephritis with programmed cell death 1 inhibitor therapy in lung cancer patients. Am J Kidney Dis. 2016;68:287-91.

111. Moussa K, Kim J, Miller JB. Retinal exudates and hemorrhages in a survivor of breast cancer. JAMA Ophthalmol. 2019;137:218-9.

112. Bommireddy T, Carrim ZI. To stop or not? Tamoxifen therapy for secondary prevention of breast cancer in a patient with ocular toxicity. BMJ Case Rep. 2016;2016:bcr2015213431.

113. Lamba N, Anderson-Nelson S. Medication induced retinal side effects. Dis Mon. 2014;60:263-7.

114. Omoti AE, Omoti CE. Ocular toxicity of systemic anticancer chemotherapy. Pharm Pract (Granada). 2006;4:55-9.

115. Elhusseiny AM, Smiddy WE. Carboplatin- and/or paclitaxel-induced ischemic retinopathy. Can J Ophthalmol. 2020;55:e95-8.

116. Reddy M, Chen JJ, Kalevar A, Terribilini R, Agarwal A. Immune retinopathy associated with nivolumab administration for metastatic non-small cell lung cancer. Retin Cases Brief Rep. 2020;14:120-6.

117. Avery RA, Trimboli-Heidler C, Kilburn LB. Separation of outer retinal layers secondary to selumetinib. J AAPOS. 2016;20:268-71.

118. van Dijk EHC, van Herpen CML, Marinkovic M, Haanen JBAG, Amundson D, Luyten GPM, et al. Serous retinopathy associated with mitogen-activated protein kinase kinase inhibition (binimetinib) for metastatic cutaneous and uveal melanoma. Ophthalmology. 2015;122:1907-16.

119. Fraunfelder FT, Fraunfelder FW. Oral anti-vascular endothelial growth factor drugs and ocular adverse events. J Ocul Pharmacol Ther. 2018;34:432-5.

120. AlAli A, Bushehri A, Park JC, Krema H, Lam WC. Pimasertib and serous retinal detachments. Retin Cases Brief Rep. 2016;10:191-6.

121. Luczkowska K, Litwinska Z, Paczkowska E, Machalinski B. Pathophysiology of drug-induce peripheral neuropathy in patients with multiple myeloma. J Physiol Pharmacol. 2018;69:165-72.

122. Morawska M, Grzasko N, Kostyra M, Wojciechowicz J, Hus M. Therapy-related peripheral neuropathy in multiple myeloma patients. Hematol Oncol. 2015;33:113-9.

123. Giannoccaro MP, Donadio V, Gomis Perez C, Borsini W, Di Stasi V, Liguori R. Somatic and autonomic small fiber neuropathy induced by bortezomib therapy: an immunofluorescence study. Neurol Sci. 2011;32:361-3.

124. Dong J, Chen H. Cardiotoxicity of anticancer therapeutics. Front Cardiovasc Med. 2018;5:9.

125. Curigliano G, Cardinale D, Dent S, Criscitiello C, Aseyev O, Lenihan D, et al. Cardiotoxicity of anticancer treatments: epidemiology, detection, and management. CA Cancer J Clin. 2016;66:309-25.

126. Vermorken JB, Remenar E, van Herpen C, Gorlia T, Mesia R, Degardin M, et al.; EORTC 24971/TAX 323 Study Group. Cisplatin, fluorouracil, and docetaxel in unresectable head and neck cancer. N Eng J Med. 2007;357:1695-704. 
127. Lamberti M, Porto S, Zappavigna S, Addeo E, Marra M, Miraglia N, et al. A mechanistic study on the cardiotoxicity of 5-fluorouracil in vitro and clinical and occupational perspectives. Toxicol Lett. 2014;227:151-6.

128. Tocchetti CG, Cadeddu C, Di Lisi D, Femminò S, Madonna R, Mele D, et al. From molecular mechanisms to clinical management of antineoplastic drug-induced cardiovascular toxicity: a translational overview. Antioxid Redox Signal. 2019;30:2110-53.

129. Swain SM, Whaley FS, Ewer MS. Congestive heart failure in patients treated with doxorubicin: a retrospective analysis of three trials. Cancer. 2003;97:2869-79.

130. Ewer MS, Vooletich MT, Durand JB, Woods ML, Davis JR, Valero V, et al. Reversibility of trastuzumabrelated cardiotoxicity: new insights based on clinical course and response to medical treatment. J Clin Oncol. 2005;23:7820-6.

131. Xiao Y, Yin J, Wei J, Shang Z. Incidence and risk of cardiotoxicity associated with bortezomib in the treatment of cancer: a systematic review and meta-analysis. PLoS One. 2014;9:e87671.

132. Larkin J, Chiarion-Sileni V, Gonzalez R, Grob JJ, Cowey CL, Lao CD, et al. Combined nivolumab and ipilimumab or monotherapy in untreated melanoma. N Engl J Med. 2015;373:23-34.

133. Minotti G, Menna P, Salvatorelli E, Cairo G, Gianni L. Anthracyclines: molecular advances and pharmacologic developments in antitumor activity and cardiotoxicity. Pharmacol Rev. 2004;56:185-229.

134. Tahover E, Segal A, Isacson R, Rosengarten O, Grenader T, Gips M, et al. Dexrazoxane added to doxorubicinbased adjuvant chemotherapy of breast cancer: a retrospective cohort study with a comparative analysis of toxicity and survival. Anticancer Drugs. 2017;28:787-94.

135. Tromp J, Steggink LC, Van Veldhuisen DJ, Gietema JA, van der Meer P. Cardio-oncology: progress in diagnosis and treatment of cardiac dysfunction. Clin Pharmacol Ther. 2017 101:481-90.

136. Bouillet B, Buffier P, Smati S, Archambeaud F, Cariou B, Vergès B. Expert opinion on the metabolic complications of mTOR inhibitors. Ann Endocrinol (Paris). 2018;79:583-90.

137. van Leeuwen RWF, Swart EL, Boom FA, Schuitenmaker MS, Hugtenburg JG. Potential drug interactions and duplicate prescriptions among ambulatory cancer patients: a prevalence study using an advanced screening method. BMC Cancer. 2010;10:679.

138. van Leeuwen RWF, Jansman FGA, van den Bemt PMLA, de Man F, Piran F, Vincenten I, et al. Drug-drug interactions in patients treated for cancer: a prospective study on clinical interventions. Ann Oncol. 2015;26:992-7.

139. Riechelmann R, Girardi D. Drug interactions in cancer patients: a hidden risk? J Res Pharm Pract. 2016;5:77-8.

140. Kubacka RT, Antal EJ, Juhl RP, Welshman IR. Effects of aspirin and ibuprofen on the pharmacokinetics and pharmacodynamics of glyburide in healthy subjects. Ann Pharmacother. 1996;30:20-6.

141. Haouala A, Widmer N, Duchosal MA, Montemurro M, Buclin T, Decosterd LA. Drug interactions with the tyrosine kinase inhibitors imatinib, dasatinib, and nilotinib. Blood. 2011;117:e75-87.

142. Busaidy NL, Farooki A, Dowlati A, Perentesis JP, Dancey JE, Doyle LA, et al. Management of metabolic effects associated with anticancer agents targeting the PI3K-Akt-mTOR pathway. J Clin Oncol. 2012;30:2919-28.

143. Clemente G, Gallo M, Giorgini M; AMD-Associazione Medici Diabetologi “Diabetes and Cancer" working group. Modalities for assessing the nutritional status in patients with diabetes and cancer. Diabetes Res Clin Pract. 2018;142:162-72.

144. Gallo M, Clemente G, Cristiano Corsi D, Michelini M, Suraci C, Farci D, et al. An integrated care pathway for cancer patients with diabetes: a proposal from the Italian experience. Diabetes Res Clin Pract. 2020;159:107721. 